Vervloet, M., Dijk, L. van, Rademakers, J.J.D.J.M., Bouvy, M.L., Smet, P.A.G.M. de, Koster, E.S. Recognizing and Addressing Limited PHarmaceutical literacy: development of the RALPH interview guide. Research in Social and Administrative Pharmacy: 2018, 14(9), 805-811

\begin{tabular}{|l|l|}
$\begin{array}{l}\text { Postprint } \\
\text { Version }\end{array}$ & 1.0 \\
\hline Journal website & https://www.rsap.org/article/S1551-7411(17)30873-2/fulltext \\
\hline Pubmed link & $\underline{\text { https://www.ncbi.nlm.nih.gov/pubmed/29724680 }}$ \\
\hline DOI & 10.1016/j.sapharm.2018.04.031
\end{tabular}

This is a NIVEL certified Post Print, more info at http://www.nivel.eu

\title{
Recognizing and Addressing Limited PHarmaceutical literacy: Development of the RALPH interview guide
}

\author{
MARCIA VERVLOET ${ }^{\mathrm{A},}$, , LISET VAN DIJK $^{\mathrm{A}}$, JANY J.D.J.M. RADEMAKERS ${ }^{\mathrm{A}, \mathrm{B}}$, MARCEL L. \\ BOUVY $^{\mathrm{C}}$, PETER A.G.M. DE SMET ${ }^{\mathrm{D}}$, DAPHNE PHILBERT ${ }^{\mathrm{C}}$, ELLEN S. KOSTER ${ }^{\mathrm{C}}$ \\ a Nivel, Netherlands Institute for Health Services Research, Utrecht, The Netherlands \\ b CAPHRI Care and Public Health Research Institute, Department of Family Medicine, \\ Maastricht University, The Netherlands \\ c Division of Pharmacoepidemiology \& Clinical Pharmacology, Utrecht Institute for \\ Pharmaceutical Sciences, Faculty of Science, Utrecht University, Utrecht, The Netherlands \\ d Radboud University Medical Center, Radboud Institute for Health Sciences, Departments \\ of Clinical Pharmacy and IQ Healthcare, Nijmegen, The Netherlands
}

\begin{abstract}
Background: In the context of medication use, pharmaceutical literacy skills are crucial for appropriate and safe use of medication. Recognition of patients with inadequate pharmaceutical literacy in daily pharmacy practice is difficult. No instrument is yet available to support pharmacists herein. The aim of this study was therefore to develop an interview guide for pharmacists to Recognize and Address Limited PHarmaceutical literacy (RALPH).

Methods: The RALPH interview guide was constructed in three phases: (1) development including a literature search, expert group discussion, and feasibility test with 15 patients; (2) pilot-test with 421 patients throughout 30 community pharmacies, and (3) final test with 508 patients to optimize the interview guide.

Results: The development phase resulted in a first interview guide comprising 15 questions: seven in the functional domain (understanding instructions), four in the communicative domain (finding and understanding medication information) and four in the critical domain (critically analyzing medication information). This version was pilot-tested in 30 pharmacies, with 147 patients during medication reviews and another 274 patients were interviewed while waiting to collect their medication. This test phase led to removal of questions that proved difficult to interpret and to rephrasing some questions. The second version including 11 questions was tested by 109 pharmacists trainees with 508 patients, resulting in the final RALPH interview guide comprising 10 questions, all directly linked to the patient's own medication: three in the functional, three
\end{abstract}


Vervloet, M., Dijk, L. van, Rademakers, J.J.D.J.M., Bouvy, M.L., Smet, P.A.G.M. de, Koster, E.S. Recognizing and Addressing Limited PHarmaceutical literacy: development of the RALPH interview guide. Research in Social and Administrative Pharmacy: 2018, 14(9), 805-811

in the communicative and four in the critical domain. Besides instructions on how to use the interview guide, recommendations are provided for pharmacists on how to support patients with limited pharmaceutical literacy skills.

Conclusions: The practice-based RALPH interview guide supports pharmacists in recognizing patients with limited pharmaceutical literacy. With this insight, pharmacists can tailor their medication counseling to patients' pharmaceutical literacy level to better support patients in their medication use.

\section{INTRODUCTION}

Health literacy refers to the skills to obtain, process and apply health information needed to make appropriate health decisions. ${ }^{1,2}$ It comprises three domains: (i) functional health literacy, referring to basic reading and writing skills necessary in everyday situations; (ii) communicative health literacy, referring to skills that allow someone to extract and understand information, and to apply new information to changing circumstances; and (iii) critical health literacy, referring to more advanced skills for critically analyzing information and using information to exert greater control over life events and situations. ${ }^{1,3}$ Limited health literacy increases the risk of poor health outcomes. $4 ; 5 ; 6 ; 7$

Health literacy skills are content and context specific. ${ }^{2}$ Persons with higher levels of general health literacy may experience difficulties in applying their skills to perform specific tasks in a specific health context. ${ }^{2}$ In the context of medication use, specific skills are required, e.g. skills to understand and apply the instructions how to use the medication, understand what the medication is for, and what its adverse effects can be. These specific skills are referred to as pharmaceutical literacy skills in this manuscript. Inadequate pharmaceutical literacy skills can lead to drug (therapy)related problems. ${ }^{8}$ Drug (therapy)-related problems cause nearly half of the potentially preventable hospital admissions.

A recent study showed that approximately half of the 984 pharmacy visitors in the Netherlands had limited health literacy skills, measured with a generic health literacy instrument. They also experienced problems with understanding medication label instructions. ${ }^{10}$ More studies have revealed patients' limited comprehension of medication label instructions and precautions or warnings accompanying the medication. ${ }^{11 ; 12 ; 13 ; 14 ; 15 ; 16}$ The pharmacy is often the last place to ensure that patients understand how to use their medication appropriately. ${ }^{17}$ It is thus crucial for pharmacists and their team to have insight in the pharmaceutical literacy skills of their patients so that they can tailor their medication counseling in a way their patients can understand. Recognizing patients with limited pharmaceutical literacy, however, is difficult. Healthcare providers often misjudge the health literacy skills of their patients. ${ }^{18}$ An earlier study showed that pharmacists mainly use their intuition or certain background characteristics (e.g. a non-native background, older age, lower educational level) to identify patients with limited health literacy skills. ${ }^{19}$ Up to now, various instruments have been developed to measure generic health literacy skills, ${ }^{20}$ and most of them mainly focus on the functional domain. An instrument to support pharmacists and their team in recognizing patients with limited pharmaceutical literacy skills is not yet available. Such an instrument should contain all three health literacy domains, as these are all important in the context of 
Vervloet, M., Dijk, L. van, Rademakers, J.J.D.J.M., Bouvy, M.L., Smet, P.A.G.M. de, Koster, E.S Recognizing and Addressing Limited PHarmaceutical literacy: development of the RALPH interview guide. Research in Social and Administrative Pharmacy: 2018, 14(9), 805-811

medication use: understanding instructions on how to use the medication (functional), asking and/or finding medication information when questions or concerns arise about e.g. potential side effects (communicative), and critically analyzing whether encountered medication information is applicable to one's own situation (critical). Additionally, many instruments measuring health literacy skills use a questionnaire that can be self-completed by patients. For patients with limited skills in the functional domain, completing a written questionnaire can already be problematic. Using an interview format, thus incorporating the questions to gain insight into patients' pharmaceutical literacy skills in the conversation (as part of pharmacists' patient counseling), can overcome this barrier. It also enables the pharmacist to further explore (and address) hesitations or uncertainties of the patient that might come up in the conversation.

Therefore, the aim of this study was to develop a practical interview guide for pharmacists and their team to Recognize and Address Limited PHarmaceutical literacy skills (RALPH).

\section{DEVELOPMENT OF THE RALPH INTERVIEW GUIDE}

The RALPH interview guide was developed in three phases (Fig. 1). This section describes each of these phases in detail.

\section{[FIGURE 1]}

\subsection{Phase 1. Development}

In June 2015, a literature search in PubMed using the terms "health literacy", "pharmaceutical literacy", "medication" and "pharmacy" was conducted to identify relevant literature regarding health literacy in the context of medication use. We reviewed studies describing instruments assessing health literacy in the functional, communicative and critical domain, as the RALPH instrument also aimed to identify skills in these three domains. Three generic instruments were identified: the Functional Communicative and Critical Health Literacy (FCCHL), ${ }^{3}$ the Health Literacy Survey EU (HLS-EU) ${ }^{21}$ and the Health Literacy Questionnaire (HLQ). ${ }^{22} \mathrm{We}$ also reviewed studies investigating patients' comprehension of medication labels with a structured interview $11 ; \underline{12} ; \underline{13} ; \underline{14} ; \underline{16}{ }^{16}$ or a survey. ${ }^{15}$

Based on the literature and the expertise of members of the project team (MV, EK, DP, MB, PdS, JR, LvD), a first draft of the RALPH interview guide was composed comprising 15 questions (Table 1). The first three questions were linked to the patient's own medication and were meant to open the conversation. The following five questions (four in the functional and one in the communicative domain) involved a hypothetical antibiotic course for pneumonia. The functional questions were related to a fictional medication label (e.g. "When should you take the medication?"). Three more questions assessed patients' communicative skills (e.g. "If you have a question about your medication, how easy or difficult is it for you to ask your healthcare provider?"). The interview guide was concluded by four questions assessing patients' ability to critically analyze medication information (e.g. "How easy or difficult is it for you to judge the quality of medication information you encounter in the media or elsewhere?") and engage in shared decision making. 
Vervloet, M., Dijk, L. van, Rademakers, J.J.D.J.M., Bouvy, M.L., Smet, P.A.G.M. de, Koster, E.S. Recognizing and Addressing Limited PHarmaceutical literacy: development of the RALPH interview guide. Research in Social and Administrative Pharmacy: 2018, 14(9), 805-811

\section{[TABLE 1]}

\subsubsection{Expert group discussion}

A group discussion was held with five pharmacists with a particular interest in communication and two communication experts involved in pharmacy practice research in September 2015 in which this first draft was discussed. They were asked to comment on the (wording of the) questions and the feasibility of the RALPH interview guide for use in daily pharmacy practice. Their main comments included:

(i) simplify the wording of some of the questions; (ii) do not let the domains determine the order of the questions, the questions should follow a regular conversation; (iii) add examples to provide context for some of the questions to enhance patients' understanding: expressing concerns about e.g. possible side effects, or asking questions about e.g. how or when to take the medication. They also suggested to create an instruction sheet accompanying the RALPH interview guide, and possibly a movie clip showing how to use the RALPH guide in the conversation with a patient. All comments were incorporated in the interview guide. An instruction sheet was created to provide pharmacists with suggestions on how to best incorporate the RALPH questions into a conversation with patients without them feeling tested or embarrassed. To this same end, a movie clip was created by members of the project team. This movie clip was made available via YouTube for pharmacists to watch before they started interviewing patients with the interview guide (in Phase 2).

\subsubsection{Feasibility test with patients}

A feasibility test to assess understanding of the questions and record the interview duration was conducted. A total of 15 patients, varying in age, gender and cultural background, in two community pharmacies who were waiting to collect their medication were interviewed with the RALPH guide by one interviewer. For six questions, three in the communicative and one in the critical domain, two types of question formats were tested: "How easy or how difficult is it to ..." versus "How much trust do you have that ..." Patients who were interviewed with the first format (easiness) understood the questions well and were better able to provide answers. This question format was implemented in the interview guide. On average, the interview took $6.9 \mathrm{~min}$ (range 4-13 $\mathrm{min}$ ), which appeared to be acceptable for patients.

\subsection{Phase 2. Pilot-test}

Between November 2015 and September 2016, the first version of the RALPH interview guide (Table 1) was pilot-tested in 30 community pharmacies throughout the Netherlands. These pharmacies are affiliated with the Utrecht Pharmacy Practice network for Education and Research (UPPER). ${ }^{23}$ The study protocol was approved by the Institutional Review Board (IRB) of the division of Pharmacoepidemiology and Clinical Pharmacology, Utrecht University (file: UP1508). Pharmacists gave verbal consent for participation in the study. In all 30 pharmacies, patients were interviewed with the RALPH interview guide by pharmacist trainees while they were waiting to collect their medication. No selection criteria in approaching patients were used, except that patients should be collecting medication for themselves. In total, 274 patients were interviewed in the waiting area of the pharmacy. Additionally, in 21 of the 30 pharmacies, the pharmacist was asked to use the RALPH interview 
Vervloet, M., Dijk, L. van, Rademakers, J.J.D.J.M., Bouvy, M.L., Smet, P.A.G.M. de, Koster, E.S. Recognizing and Addressing Limited PHarmaceutical literacy: development of the RALPH interview guide. Research in Social and Administrative Pharmacy: 2018, 14(9), 805-811

guide during five regularly scheduled medication reviews. Patients eligible for these medication reviews were 65 years or older and used a minimum of five medicines. A total of 147 patients were interviewed with the RALPH guide during their medication review. All patients were asked to provide informed consent. Pharmacists received a small fee (25 euros per patient) to use RALPH during these medication reviews. Afterwards, the 21 pharmacists were asked to complete an online questionnaire about their experiences with RALPH. Thirteen pharmacists completed this questionnaire. Overall, the pharmacists had positive experiences with the interview guide. All pharmacists indicated that the interview guide and accompanying instruction sheet were clear. Nine pharmacists thought the interview questions were clear for patients. Eight pharmacists indicated that by using the RALPH interview guide they were able to recognize patients with limited pharmaceutical literacy skills. The experiences of the pharmacists and pharmacist trainees were used to further optimize the RALPH interview guide.

The pilot-test led to the following adjustments to the RALPH interview guide (Table 2):

- The five questions (four in the functional and one in the communicative domain) involving the hypothetical antibiotic course for pneumonia were deleted. It appeared to be difficult for patients to interpret a hypothetical medication treatment; patients got confused as they indicated they were not taking antibiotics at the moment. Linking the questions to patients' own medication appeared to be a better method for exploring functional literacy. This would also make it easier for pharmacists to incorporate the RALPH questions in their patient counseling.

- One question was added in the functional domain to explore patients' understanding of possible precautions or warnings applicable to their own medication.

- The wording of a question in the critical domain was adjusted: judging the quality of information (both reliability and correctness) became judging the reliability of information. Patients had difficulties in interpreting what was meant by quality of information.

[TABLE 2]

The second version of the RALPH interview guide comprised 11 questions.

\subsection{Phase 3. Final test}

From January to July 2017, the second version of the RALPH interview guide was tested by 109 pharmacist(s) trainees (36 master students and 72 pharmacists following the advanced community pharmacist education program). They each interviewed three to five patients with the RALPH interview guide, leading up to a total of 508 interviewed patients. Besides the RALPH questions, patients were also interviewed with the Functional, Communicative and Critical Health Literacy scale $\left(\right.$ FCCHL) ${ }^{3}$ for comparison purposes. Details on the agreement of the RALPH interview guide and the FCCHL in recognizing low health literacy levels are described elsewhere in this issue. ${ }^{24}$

This final test led to one last adjustment to the RALPH interview guide. Two questions in the functional domain - how do you take your medicine and when do you take your medicine - were combined as patients often combined both aspects in 
Vervloet, M., Dijk, L. van, Rademakers, J.J.D.J.M., Bouvy, M.L., Smet, P.A.G.M. de, Koster, E.S. Recognizing and Addressing Limited PHarmaceutical literacy: development of the RALPH interview guide. Research in Social and Administrative Pharmacy: 2018, 14(9), 805-811

one answer. The instruction sheet was further optimized by incorporating interpretation of the answers and recommendations for pharmacists regarding how to support patients with low pharmaceutical literacy skills.

\section{THE FINAL RALPH INTERVIEW GUIDE}

The final RALPH interview guide (included in Appendix 1) comprises 10 questions, all directly linked to the patient's own medication, in the three pharmaceutical literacy domains: three questions in the functional domain (understanding medication use instructions), three questions in the communicative domain (finding and understanding medication information) and four questions in the critical domain (critically analyzing information). A condensed version of the instruction sheet (recommendations and advice specific to the Dutch situation are left out) is also included in Appendix 1.

\subsection{How to use the RALPH interview guide in daily practice}

To facilitate pharmacists in registering patients' answers easily, possible answers are pre-printed on the interview guide. In the functional domain, the pharmacist can register the answer itself, whether this was correct or not, or whether the patient did not know the answer. For most of the questions in the communicative and critical domain, pharmacists can register whether patients indicated the action (e.g. asking questions or judging the reliability of information) was (very) difficult or (very) easy for them to perform. It should, however, be emphasized that open-ended questions need to be used. For some of the questions, e.g. judging information on its reliability or its relevance, patients might indicate that the question is not applicable to them. They may never search for (understandable) information or never come across any information in the media or elsewhere. The pharmacist should, however, be aware that this answer can also indicate that the patient experiences difficulties in searching or judging information, and therefore never takes these actions. Further exploring reasons behind such an answer is thus important.

With the RALPH interview guide insight can be gained into the three domains of pharmaceutical literacy. The pharmacist may ask a subset of questions to gain insight into a particular domain. For some patients, for example, the first three questions of the RALPH guide (the functional domain) might already reveal patients' misunderstanding of label instructions and identify inappropriate use of the medication. With other patients, the pharmacist may only incorporate the questions from the communicative or/and the critical domain to gain insight into patients' skills in these domains, when the pharmacist is sure that the medication instructions are well understood.

In daily busy practice, it may not be feasible nor desirable to ask the questions incorporated in the RALPH interview guide for each individual medicine the patient might use, as this would create a large time burden for both the patient and the pharmacist. The pharmacist may choose one of the medicines with e.g. a more complex regime, special instructions, or with known problems (e.g. nonadherence). This might already be sufficient to gain insight into the patients' pharmaceutical literacy skills in general.

The RALPH interview guide was tested during several patient encounters (i.e. during a medication review, at the pharmacy counter, while waiting to pick up medication). Incorporating the RALPH questions during all these encounters appeared feasible: the majority of pharmacists indicated that the interview guide was a suitable and 
Vervloet, M., Dijk, L. van, Rademakers, J.J.D.J.M., Bouvy, M.L., Smet, P.A.G.M. de, Koster, E.S. Recognizing and Addressing Limited PHarmaceutical literacy: development of the RALPH interview guide. Research in Social and Administrative Pharmacy: 2018, 14(9), 805-811

practical tool for recognizing patients with limited pharmaceutical literacy skills in busy daily pharmacy practice. Moreover, they reported that the RALPH questions and the instruction sheet were clear and easy to use.

\subsubsection{Interpretation of answers}

The RALPH interview guide was developed as a practical and feasible instrument to use in daily pharmacy practice. All questions are linked to the patient's own medication, which enables the pharmacist to easily incorporate the questions in the conversation with the patient during a regular pharmacy visit. It also enables patients to easily relate to the questions (also shown by the difficulties some patients had in interpreting a hypothetical antibiotic course). The RALPH questions provide the pharmacist with an indication (not an objective score) of whether a patient experiences difficulties in one or more pharmaceutical literacy domains. This insight assists the pharmacist in tailoring the provision of information to the patients' level of understanding. Moreover, it enables pharmacists to ensure that their patients safely and appropriately take their own medication.

In the functional domain, limited skills are indicated by patients incorrectly answering or not knowing why or how to use the medication or how to interpret a precaution or warning. Pharmacists may, for example, include visual information (pictograms or video-animations) about the medication treatment. For both the communicative and the critical domain, limited skills are indicated by patients pointing out that a certain action (e.g. asking the healthcare provider questions or judging the reliability of information) is (very) difficult for them to perform, and may also be indicated by patients answering that the question is not applicable to them (e.g. not searching for information or encountering information or engaging in shared decision making). To support patients having difficulties in the communicative or critical domain, e.g. with finding understandable and/or reliable information, pharmacists can, for example, refer patients to reliable information sources.

\section{DISCUSSION}

In this study, a practice-based interview guide for pharmacists and their team to recognize patients with limited pharmaceutical literacy skills in daily pharmacy practice was developed: the RALPH interview guide. Up to now, no such instrument was available whilst it is essential for pharmacists to gain insight into their patients' pharmaceutical literacy skills so that they can tailor their medication information to the patient's needs and ensure that their patients use their medication safely and appropriately.

Whereas most generic health literacy instruments focus mainly on the functional health literacy skills, ${ }^{20}$ the RALPH interview guide represents all three domains of health literacy - functional, communicative and critical domain. Heijmans et al. showed that communicative and critical health literacy skills are more strongly associated with aspects of self-management (which includes medication use) than functional health literacy skills, emphasizing the importance of including all three domains. $^{25}$

The questions of the RALPH interview guide can be easily incorporated in a regular patient encounter. This requires, however, adequate communication skills of the pharmacist. Further training on how to best provide counseling to patients with limited pharmaceutical literacy skills might be useful. An educational package 
Vervloet, M., Dijk, L. van, Rademakers, J.J.D.J.M., Bouvy, M.L., Smet, P.A.G.M. de, Koster, E.S. Recognizing and Addressing Limited PHarmaceutical literacy: development of the RALPH interview guide. Research in Social and Administrative Pharmacy: 2018, 14(9), 805-811

developed in the Australian HeLP (Health Literacy in Pharmacy) project appeared to be effective in improving some aspects of communication by pharmacists and pharmacy staff with low literate consumers. ${ }^{26}$

It is important for pharmacists and their team to be aware of ways regarding how to best support patients with limited pharmaceutical literacy skills. A recent systematic review revealed that the most effective interventions to support patients with limited health literacy skills included additional aids that enforce written information (e.g. pictograms, animations or verbal information), information tailored to the patient's needs, information that is easy to navigate (e.g. use of bullets, larger font size, shorter sentences) and information that is easily accessed (e.g. an illustrated pill card to post on the refrigerator or keep in a wallet). ${ }^{27}$ These interventions led to improved medication knowledge and adherence.

\subsection{Strengths and limitations}

Pharmacists (trainees), patients and communication experts were involved in the development of the RALPH interview guide. Pharmacists (trainees) were asked to share their experiences with using the interview guide during daily patient encounters. Their suggestions for improvement were incorporated in the final interview guide. As such, we ensured that the final interview guide met the needs of pharmacists and is feasible for use in daily (busy) practice. In addition, the interview guide was evaluated extensively during different patient encounters: during medication reviews with older patients and at the pharmacy counter with patients who filled their prescriptions. It shows feasibility and usability of the interview guide in all these encounters.

Because of the linkage of the RALPH questions to patients' own medication - which can vary between patients in complexity and duration of use (and therefore in familiarity with the medication) an objective score to classify patients with low, moderate or high literacy cannot easily be calculated. This hinders use of the interview guide for research purposes.

\subsection{Implications for practice and research}

The RALPH interview guide has been developed for use in the pharmacy setting. However, in every setting in which medication use is being discussed with patients, the RALPH interview guide can be a useful tool to recognize patients with limited pharmaceutical literacy skills who have an increased risk of drug related problems, such as non-adherence. The interview guide could, for example, also be used in general practice, in the hospital setting during admission or discharge consultations, or even at home by nurses in home care.

Patients' pharmaceutical literacy levels as assessed with the RALPH interview guide are described elsewhere in this issue. ${ }^{24}$ Briefly, that study showed the usefulness of the RALPH guide in recognizing difficulties pharmacy visitors experience with understanding, processing and applying medication information. Future research may further explore how the RALPH interview guide can be used in specific situations, e.g. understanding and applying medication instructions before and after a surgery.

\section{CONCLUSIONS}

The practice-based RALPH interview guide supports pharmacists and their team in recognizing patients with limited pharmaceutical literacy skills. With this insight, 
Vervloet, M., Dijk, L. van, Rademakers, J.J.D.J.M., Bouvy, M.L., Smet, P.A.G.M. de, Koster, E.S. Recognizing and Addressing Limited PHarmaceutical literacy: development of the RALPH interview guide. Research in Social and Administrative Pharmacy: 2018, 14(9), 805-811

they can tailor their medication counseling to patients' pharmaceutical literacy levels to better support patients in safe and appropriate use of medications.

\section{Funding}

This study was financed by a research grant from the Royal Dutch Pharmacist Association (KNMP).

\section{Conflicts of interest}

The authors report no conflicts of interest related to this study.

\section{Acknowledgements}

The authors wish to thank all the pharmacists, pharmacist trainees and patients who were willing to participate in the study.

\section{[APPENDIX A. SUPPLEMENTARY DATA}

\section{REFERENCES}

1 D. Nutbeam Health literacy as a public health goal: a challenge for contemporary health education and communication strategies into the 21st century Health Promot Int, 15 (2000), pp. 259-267

$2 \mathrm{D}$. Nutbeam Defining and measuring health literacy: what can we learn from literacy studies? Int J Publ Health, 54 (5) (2009), pp. 303-305

$3 \mathrm{H}$. Ishikawa, T. Takeuchi, E. Yano Measuring functional, communicative, and critical health literacy among diabetic patients Diabetes Care, 31 (5) (2008), pp. 874-879

4 N.D. Berkman, S.L. Sheridan, K.E. Donahue, D.J. Halpern, K. Crotty Low health literacy and health outcomes: an updated systematic review Ann Intern Med, 155 (2) (2011), pp. 97-107

5 D.A. DeWalt, A. Hink Health literacy and child health outcomes: a systematic review of the literature Pediatrics, 124 (Suppl. 3) (2009), pp. S265-S274

6 J.A. Gazmararian, M.V. Williams, J. Peel, D.W. Baker Health literacy and knowledge of chronic disease Patient Educ Counsel, 51 (3) (2003), pp. 267-275

7 J. Rademakers Gezondheidsvaardigheden: niet voor iedereen vanzelfsprekend Nivel, Utrecht (2014)

$8 \mathrm{H}$. Wali, K. Grindrod Don't assume the patient understands: qualitative analysis of the challenges low health literate patients face in the pharmacy Res Soc Adm Pharm, 12 (6) (2016), pp. 885-892 https://doi-org.proxy.library.uu.nl/10.1016/j.sapharm.2015.12.003 Nov - Dec, Epub 2016 Jan 5

9 A.J. Leendertse, A.C. Egberts, L.J. Stoker, P.M. van den Bemt, H.S. Group Frequency of and risk factors for preventable medication-related hospital admissions in The Netherlands Arch Intern Med, 168 (17) (2008), p. 1890

10

E.S. Koster, D. Philbert, M.L. Bouvy

Health literacy among pharmacy visitors in The Netherlands

Pharmacoepidemiol Drug Saf, 24 (7) (2015 Jul), pp. 716-721 https://doi-

org.proxy.library.uu.nl/10.1002/pds. 3803 Epub 2015 May 27

11T.C. Davis, M.S. Wolf, P.F. Bass 3rd, et al. Low literacy impairs comprehension of prescription drug warning labels J Gen Intern Med, 21 (8) (2006), pp. 847-851

12 T.C. Davis, M.S. Wolf, P.F. Bass 3rd, et al. Literacy and misunderstanding prescription drug labels Ann Intern Med, 145 (12) (2006), pp. 887-894

13 M.S. Wolf, T.C. Davis, H.H. Tilson, P.F. Bass 3rd, R.M. Parker Misunderstanding of prescription drug warning labels among patients with low literacy Am J Health Syst Pharm, 63 (11) (2006 Jun 1), pp. 1048-1055

14 M.S. Wolf, T.C. Davis, W. Shrank, et al. To err is human: patient misinterpretations of prescription drug label instructions Patient Educ Counsel, 67 (3) (2007), pp. 293-300 
Vervloet, M., Dijk, L. van, Rademakers, J.J.D.J.M., Bouvy, M.L., Smet, P.A.G.M. de, Koster, E.S. Recognizing and Addressing Limited PHarmaceutical literacy: development of the RALPH interview guide. Research in Social and Administrative Pharmacy: 2018, 14(9), 805-811

15 E.S. Koster, L. Blom, N.A. Winters, R.P. van Hulten, M.L. Bouvy Interpretation of drug label instructions: a study among four immigrant groups in The Netherlands Int $\mathrm{J}$ Clin Pharm, 36 (2) (2014 Apr), pp. 274-281

16 L.M. Emmerton, L. Mampallil, T. Kairuz, L.M. McKauge, R.A. Bush Exploring health literacy competencies in community pharmacy Health Expect, 15 (1) (2012), pp. 12-22

17 J.L. Johnson, L. Moser, C.L. Garwood Health literacy: a primer for pharmacists Am J Health Syst Pharm, 70 (11) (2013 Jun 1), pp. 949-955 https://doiorg.proxy.library.uu.nl/10.2146/ajhp120306

18 M. Ohl, A. Harris, D. Nurudtinova, X. Cai, D. Drohobyczer, E.T. Overton Do brief screening questions or provider perception accurately identify persons with low health literacy in the HIV primary care setting? AIDS Patient Care STDS, 24 (10) (2010), pp. 623629

19 E.S. Koster, D. Philbert, L. Blom, M.L. Bouvy "These patients look lost" - community pharmacy staff's identification and support of patients with limited health literacy Int $\mathrm{J}$ Pharm Pract, 24 (6) (2016 Dec), pp. 403-410 https://doiorg.proxy.library.uu.nl/10.1111/ijpp.12272 Epub 2016 May 4

20 J.N. Haun, M.A. Valerio, L.A. McCormack, K. Sørensen, M.K. Paasche-Orlow Health literacy measurement: an inventory and descriptive summary of 51 instruments $\mathrm{J}$ Health Commun, 19 (Suppl. 2) (2014), pp. 302-333 https://doiorg.proxy.library.uu.nl/10.1080/10810730.2014.936571

21 K. Sørensen, S. Van den Broucke, J.M. Pelikan, et al. HLS-EU Consortium. Measuring health literacy in populations: illuminating the design and development process of the European Health Literacy Survey Questionnaire (HLS-EU-Q) BMC Publ Health, 13 (2013 Oct 10), p. 948 https://doi-org.proxy.library.uu.nl/10.1186/1471-2458-13-948

22 R.H. Osborne, R.W. Batterham, G.R. Elsworth, M. Hawkins, R. Buchbinder The grounded psychometric development and initial validation of the Health Literacy Questionnaire (HLQ) BMC Publ Health, 13 (2013 Jul 16), p. 658 https://doi-org.proxy.library.uu.nl/10.1186/14712458-13-658

23 E.S. Koster, L. Blom, D. Philbert, W. Rump, M.L. Bouvy The Utrecht Pharmacy Practice network for Education and Research: a network for community and hospital pharmacies in The Netherlands Int J Clin Pharm, 36 (4) (2014), pp. 669-674

24 E.S. Koster, D. Philbert, L. van Dijk, et al. Recognizing pharmaceutical illiteracy in community pharmacy: agreement between a practice-based interview guide and questionnaire based assessment Res Soc Adm Pharm (2018 Feb 2) https://doiorg.proxy.library.uu.nl/10.1016/j.sapharm.2018.01.009 pii: S1551-7411(17)30824-0. [Epub ahead of print]

25 M. Heijmans, G. Waverijn, J. Rademakers, R. van der Vaart, M. Rijken Functional, communicative and critical health literacy of chronic disease patients and their importance for self-management Patient Educ Counsel, 98 (1) (2015 Jan), pp. 41-48 https://doiorg.proxy.library.uu.nl/10.1016/j.pec.2014.10.006 Epub 2014 Oct 16

26 Duncan, G, Emmerton, L, Hussainy, S, et al. HeLP: Health Literacy in Pharmacy Project. From: http://6cpa.com.au/resources/fifth-agreement-rd/health-literacy-project/.

$27 \mathrm{H}$. Wali, Z. Hudani, S. Wali, K. Mercer, K. Grindrod A systematic review of interventions to improve medication information for low health literate populations Res Soc Adm Pharm, 12 (6) (2016), pp. 830-864 https://doi-org.proxy.library.uu.nl/10.1016/j.sapharm.2015.12.001 Nov - Dec, Epub 2015 Dec 17 
Vervloet, M., Dijk, L. van, Rademakers, J.J.D.J.M., Bouvy, M.L., Smet, P.A.G.M. de, Koster, E.S. Recognizing and Addressing Limited PHarmaceutical literacy: development of the RALPH interview guide. Research in Social and Administrative Pharmacy: 2018, 14(9), 805-811

\section{TABLES AND FIGURE}

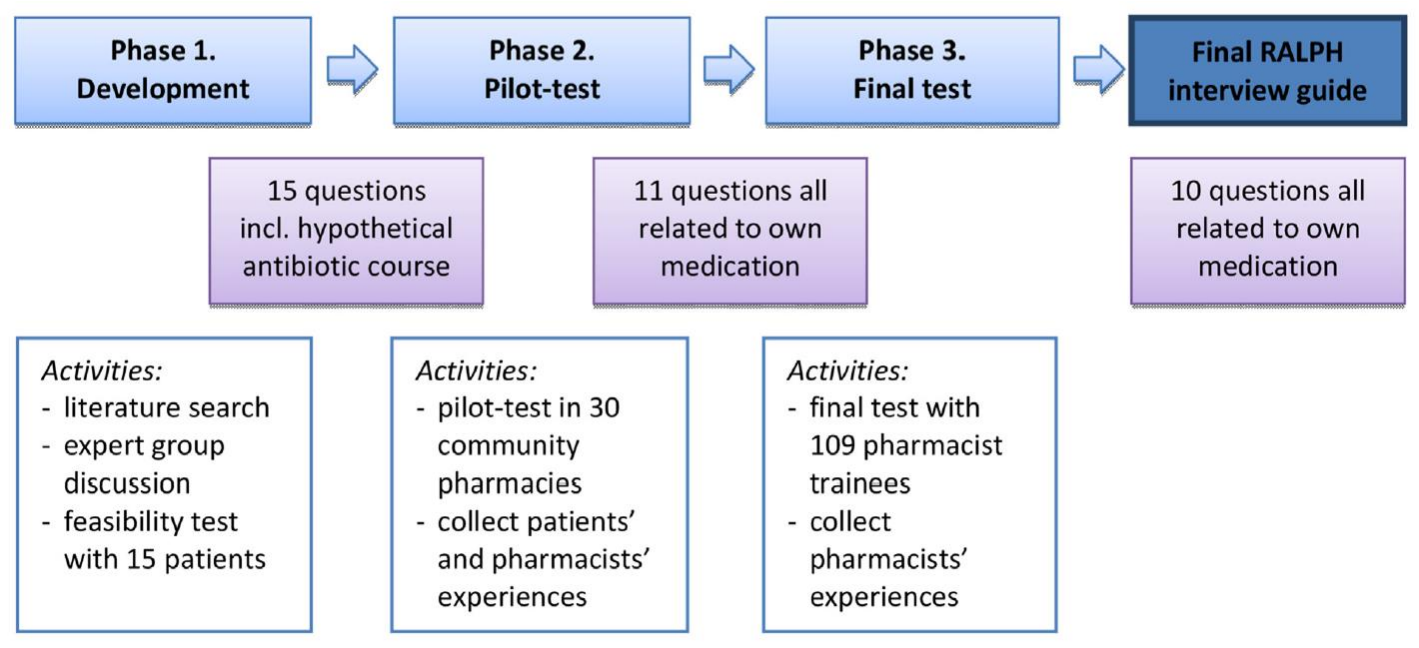

Fig. 1. Development of the RALPH interview guide in three phases.

Table 1. The first version of the RALPH interview guide comprising 15 questions.

\begin{tabular}{|c|c|}
\hline $\begin{array}{l}\text { Literacy domain } \\
\text { (nr. of questions) }\end{array}$ & Topics \\
\hline Functional (3) & $\begin{array}{l}3 \text { questions investigated patients' understanding of use instructions of } \\
\text { their own medication. These questions were meant to open the } \\
\text { conversation. }\end{array}$ \\
\hline \multirow[t]{2}{*}{ Functional (4) } & $\begin{array}{l}4 \text { questions involved a hypothetical antibiotic course for pneumonia for } \\
\text { which a fictional medication label was provided with the following use } \\
\text { instructions and precaution: "Use one tablet three times daily for } 7 \text { days. } \\
\text { A half an hour before or } 2 \text { h after a meal. Finish the course. Do not drink } \\
\text { grapefruit juice while taking this medicine." }\end{array}$ \\
\hline & $\begin{array}{l}\text { The questions investigated patients' understanding of these instructions } \\
\text { and their numeracy skills. }\end{array}$ \\
\hline \multirow[b]{2}{*}{ Communicative (4) } & $\begin{array}{l}1 \text { question was linked to the hypothetical pneumonia case, and } \\
\text { investigated whether patients would contact their healthcare provider in } \\
\text { case of persisting symptoms after completion of the antibiotic course. }\end{array}$ \\
\hline & $\begin{array}{l}3 \text { questions investigated the easiness with which patients ask their } \\
\text { healthcare provider questions and express concerns about their } \\
\text { medication, and find understandable information regarding their } \\
\text { (medication) treatment. }\end{array}$ \\
\hline \multirow[t]{2}{*}{ Critical (4) } & $\begin{array}{l}3 \text { questions investigated the easiness with which patients judge the } \\
\text { quality of information (reliability of source or correctness of information) } \\
\text { encountered in the media or elsewhere, judge the applicability of this } \\
\text { information to their own situation, and engaged in shared decision making } \\
\text { about their (medication) treatment. }\end{array}$ \\
\hline & $\begin{array}{l}1 \text { question investigated how patients handle contradictory information } \\
\text { about their medication. }\end{array}$ \\
\hline
\end{tabular}


Vervloet, M., Dijk, L. van, Rademakers, J.J.D.J.M., Bouvy, M.L., Smet, P.A.G.M. de, Koster, E.S. Recognizing and Addressing Limited PHarmaceutical literacy: development of the RALPH interview guide. Research in Social and Administrative Pharmacy: 2018, 14(9), 805-811

Table 2. Adjustments to the first version of the RALPH interview guide based on the results from phase 2 , resulting in a second version comprising 11 questions in the three domains.

\begin{tabular}{|c|c|c|}
\hline $\begin{array}{c}\text { Literacy } \\
\text { domain }\end{array}$ & Topics removed & Remaining topics \\
\hline \multirow[b]{2}{*}{ Functional } & \multirow{2}{*}{$\begin{array}{l}4 \text { questions linked to } \\
\text { the hypothetical } \\
\text { antibiotic course for } \\
\text { pneumonia }\end{array}$} & $\begin{array}{l}3 \text { questions assessing patients' understanding of use } \\
\text { instructions of their own medication }\end{array}$ \\
\hline & & $\begin{array}{l}\text { Added question: patients' understanding of a } \\
\text { precaution or warning if their own medication carried } \\
\text { one }\end{array}$ \\
\hline Communicative & $\begin{array}{l}1 \text { question linked to the } \\
\text { hypothetical pneumonia }\end{array}$ & $\begin{array}{l}3 \text { questions assessing patients' ability to ask their } \\
\text { healthcare provider questions, express concerns about } \\
\text { their medication, and find understandable } \\
\text { (medication) information. }\end{array}$ \\
\hline \multirow[t]{2}{*}{ Critical } & \multirow[t]{2}{*}{ None } & $\begin{array}{l}3 \text { questions assessing patients' ability to judge the } \\
\text { reliability(rephrased) and applicability of } \\
\text { (medication) information, and engage in shared } \\
\text { decision making. }\end{array}$ \\
\hline & & 1 question on handling contradictory information. \\
\hline
\end{tabular}

